\title{
Removing Methylene Blue from Aqueous Solutions Using Rice Husk Silica Adsorbent
}

\author{
Khalilollah Moeinian, Seyed Mahmoud Mehdinia* \\ Department of Environmental Health Engineering, Semnan University of Medical Sciences, Semnan, Iran
}

\author{
Received: 11 March 2018 \\ Accepted: 14 May 2018
}

\begin{abstract}
The main goal of this study is to investigate the efficiency of the silica derived from the raw rice husk in the removal of methylene blue from aqueous solutions. The effects of initial concentrations of methylene blue, $\mathrm{pH}$, the adsorbent dose, and the contact time on methylene blue removal efficiency were carried out in batch reactors. The silica derived from the raw rice husk was prepared in a furnace at $800^{\circ} \mathrm{C}$ for 4 hours after acid leaching with sulfuric acid and chloridric acid. The rice husk silica showed more porosity than the raw rice husk with a median pore radius of $2.4 \mathrm{~nm}$ and a high specific surface area up to $226.3 \mathrm{~m}^{2} \mathrm{~g}^{-1}$. The maximum removal efficiency of methylene blue by the rice husk silica under the initial concentration of $10 \mathrm{mgL}^{-1}$ methylene blue, $1 \mathrm{gL}^{-1}$ adsorbent mass, 60 min contact time, and pH 8 was $96.7 \%$. Correlation coefficients of the adsorption models have shown a better matching of methylene blue adsorption by the rice husk silica with the Langmuir isotherm model. The results of this study show that the rice husk silica can be applied to remove environmental pollutants such as methylene blue due to the low cost and availability of rice husks.
\end{abstract}

Keywords: adsorption, isotherm, methylene blue, rice husk silica

\section{Introduction}

Preserving the environment from modern technology and industrial pollution is a prime concern of today, for such pollution endangers social public health. The discharge of colored wastewaters of different industries, such as textiles, papers, cosmetics, agriculture, plastics, and leather, results in severe environmental problems because the toxicity of some dyestuff damages not only the natural landscape, but also the aqua ecosystems $[1,2]$. With regard to the increase of different types of pollutants in water resources and scarcity of healthy

*e-mail: smmehdinia@yahoo.ca water, countries are required to take measures and think of strategies for reuse as a national priority [3]. The textile industry is one of the biggest users of water in the world. Colors, one of the most dangerous environment pollutants, are in the wastewaters of this industry, which pollutes the environment and human life $[4,5]$. The color methylene blue with the chemical formula $\mathrm{C}_{16} \mathrm{H}_{18} \mathrm{ClN}_{3} \mathrm{~S}$, whose chemical structure is shown in Fig. 1, is a multiple core aromatic compound. Moreover, it is one of the most widely used cationic colors in the textile industry; it is used for dyeing wool, cotton, and silk cloth $[6,7]$.

Owing to their complex structures, colors are often stable and resistant to biological degradation that is toxic, carcinogenic, and capable of mutagenesis [8]. Sore 
<smiles>CCNC1=CC2Sc3cc(NCC)c(C)cc3N=C2C=C1C</smiles>

Fig. 1. Chemical structure of methylene blue [6].

eyes, nausea, diarrhea, and vomiting are the side effects of methylene blue wastewater observed in human [7, 9]. Colors are the most dangerous chemical compounds found in industrial wastewaters; they can cause allergies, dermatitis, skin irritation, cancer, and genetic mutations in humans [9]. In addition, discharge of such wastewaters results in reduced sunlight penetration, outbreaks of eutrophication phenomena, and disturbance in the receiving water ecology. This not only affects the photosynthesis of aquatic plants and algae, but also damages the environment [10].

Removal of color from industrial wastewaters, especially textile and color factories, has always been an important action for controlling pollution. Minor amounts of color in water reduce the transparency of water and the concentration of dissolved oxygen in water; therefore, they threaten the aquatic life of the receiving environment [4]. Contamination of the color compounds in the textile industry is generally related to dying, printing, and finishing fabrics as well as washing the coloring casseroles and devices [11]. To remove or reduce color, different methods are applied to chemical coagulation and flocculation, adsorption, electrochemistry, reverse osmosis, and photochemical oxidation. Each of these methods has its own advantages and disadvantages. For instance, a huge amount of sludge is produced in the coagulation and flocculation method. High pressure is required in reverse osmosis, which increases energy consumption. In the photochemical oxidation method, UV rays in the presence of oxidizing agents, such as catalysts and peroxides, are not expandable economically; moreover, they produce additional and secondary products [4, 12]. Adsorption is an effective method for removing colors from wastewater. Different adsorbents like activated carbon, date fiber, sawdust, oat bran, and chitosan were studied for this method [10, 11]. Highly efficient commercially activated carbon is expensive and therefore environmental and environmental health engineers consider inexpensive absorbents from agricultural wastes [5, 13-18]. Agricultural wastes are the most applicable and use bioabsorbents. Low cost, high efficiency, lowest waste, and recyclable waste and remains are the advantages of such compounds [18, 19].

Rice husks are a secondary and additional product of rice; it composes, on average, about $20 \%$ of rice weight. More than 115 million tons of rice husk are produced around the world annually. Their disposal and discharge is an environmental problem for developing countries. Although the use of agricultural waste, such as rice husks, to remove different environmental pollutants, such as heavy metals and air pollutants, in many research studies is efficient and shows good performance [16], there is no report form reliable scientific resources on the removal of methylene blue from aquatic solutions by using the rice husk silica. Therefore, this study investigates the capability of the rice husk silica in the removal of methylene blue form aquatic solutions.

\section{Materials and Methods}

This is a laboratory study conducted to study the efficiency of the rice husk silica in the removal of methylene blue. It was conducted in the chemistry laboratory of the Faculty of Health in Damghan (Semnan University of Medical Sciences) in 2016.

\section{Preparing the Absorbents}

Raw rice husk was procured from rice factories in northern Iran. To produce the rice husk silica, we washed the raw husk with pipe water to make it clean. Then we put it under the temperature of $110^{\circ} \mathrm{C}$ for 24 hours to dry. Next, we conducted acid leaching with chloride acid $3 \%$ and sulfuric acid $10 \%$ for two hours. The ratio was $50 \mathrm{~g}$ rice husk and a $1 \mathrm{~L}$ combination of these two acids. Afterward, we washed the pickled rice husk with distilled water several times. Finally, we put it in a muffle furnace at $800^{\circ} \mathrm{C}$ for four hours to prepare silica and use it as a natural absorbent [17].

\section{Batch Experiments}

To conduct experiments on the methylene blue adsorption by the rice husk silica, we first prepared a methylene blue stock solution with a concentration of $1,000 \mathrm{mgL}^{-1}$. Then, to draw the calibration curve, we prepared solution samples with concentrations of 0.1 , $0.2,0.3,0.4$, and $0.5 \mathrm{mgL}^{-1}$ [20]. We studied different concentrations of methylene blue $(10,50,75$, and 100 $\mathrm{mgL}^{-1}$ ) to determine the removal efficiency of the initial concentration of methylene blue on the removal efficiency by the adsorbent. We also studied the effects of acidic and alkaline $\mathrm{pH}$ conditions on the removal efficiency of methylene blue at different $\mathrm{pH}(5,6,7$, 8 , and 9). This study also determined the effect of the dose of the used adsorbent $\left(0.5,1,1.5\right.$, and $\left.2 \mathrm{gL}^{-1}\right)$ by adding normal sulfuric acid and sodium hydroxide 0.1 and 1, respectively [21]. Moreover, this study determined the effects of different contact times $(30,45,60,75$, and $90 \mathrm{~min})[16]$.

The surface morphology and pores of the adsorbent were observed under a scanning electron microscope (SEM) using LEO operated at accelerating voltage of $15 \mathrm{kV}$. Moreover, The Brunauer-Emmett-Teller (BET) specific surface area was done with the use of a ThermoFinnigan Sorptomatic apparatus using nitrogen adsorption at $-196^{\circ} \mathrm{C}$ [23]. The removal efficiency of 
methylene blue using rice husk silica was calculated by Eq. (1):

$$
\mathrm{RE}=\frac{c_{\mathrm{Gi}}-c_{\mathrm{G}}}{c_{\mathrm{Gi}}} \times 100
$$

...where $\left(\mathrm{C}_{\mathrm{Gi}}\right)$ is the initial concentration of methylene blue $\left(\mathrm{mgL}^{-1}\right), \mathrm{C}_{\mathrm{Go}}$ is the secondary methylene blue concentration $\left(\mathrm{mgL}^{-1}\right)$, and $\mathrm{RE}$ denotes the removal efficiency $(\%)$ [24-26].

\section{Results and Discussion}

\section{The Properties of Adsorbent (Rice Husk Silica)}

The Brunauer-Emmett-Teller (BET) specific surface area was performed with the use of a ThermoFinnigan Sorptomatic apparatus using nitrogen adsorption at $-196^{\circ} \mathrm{C}$. The BET value obtained for rice husk silica, which was prepared at $800^{\circ} \mathrm{C}$, was $226.3 \mathrm{~m}^{2} \mathrm{~g}^{-1}$. This type of silica was shown to be mesoporous with a median pore radius of $2.4 \mathrm{~nm}$. The surface area (BET) 2 parameters line $\left(\mathrm{p} / \mathrm{p}^{\mathrm{o}} \mathrm{Vs} \cdot \mathrm{p} /\left(\mathrm{V}_{\text {ads }}\left(\mathrm{p}^{\mathrm{o}}-\mathrm{p}\right)\right) / \mathrm{cm}^{-3} \mathrm{~g}\right.$ is shown in Fig. 2, while the pore radius size $(\mathrm{nm})$ versus pore volume $\left(\mathrm{cm}^{3} \mathrm{~g}^{-1}\right)$ is depicted in Fig. 3. Some of the most important physical and chemical characteristics of the silica that was prepared from rice husk and used as adsorbent in this study are shown in Table 1.

Both the shape and pores of the rice husk silica and raw rice husk were studied using a scanning electron

Table 1. Important physical and chemical properties of the rice husk silica used as adsorbent.

\begin{tabular}{|c|c|c|}
\hline Properties & Unit & Value \\
\hline Surface area & $\left(\mathrm{m}^{2} \mathrm{~g}^{-1}\right)$ & 226.3 \\
\hline Median pore radius & $(\mathrm{nm})$ & 2.4 \\
\hline Analysis of Elements: & $(\%)$ & \\
\hline $\mathrm{C}$ & & $0.05 \pm 0.01$ \\
\hline $\mathrm{H}$ & & $0.27 \pm 0.01$ \\
\hline $\mathrm{N}$ & & $0.36 \pm 0.05$ \\
\hline S & & $0.03 \pm 0.01$ \\
\hline Chemical Composition: & $(\%)$ & \\
\hline $\mathrm{SiO}_{2}$ & & 97.35 \\
\hline $\mathrm{SO}_{3}$ & & 1.66 \\
\hline $\mathrm{K}_{2} \mathrm{O}$ & & 0.43 \\
\hline $\mathrm{CaO}$ & & 0.27 \\
\hline $\mathrm{Fe}_{2} \mathrm{O}_{3}$ & & 0.15 \\
\hline $\mathrm{MnO}$ & & 0.10 \\
\hline $\mathrm{ZnO}$ & & 0.04 \\
\hline
\end{tabular}

microscope (SEM) using LEO operated at accelerating voltage of $15 \mathrm{kv}$. Fig. 4 illustrates the shapes and pores of the rice husk silica, with magnifications of (a) 1000 and (b) 2000. The SEM of raw rice husk with magnifications of (a) 500 and (b) 1000 times are shown in Fig. 5. As seen in the comparison of Figs 4 and 5, the rice husk silica showed more porosity than the raw rice husk. More porosity of adsorbents causes more removal efficiency because of its numbers of adsorption sites [27].

\section{Results of the pH Effect}

One of the important parameters in the adsorption process is the amount of the $\mathrm{pH}$ value of the aqueous solution $[28,29]$. In this study, the effect of the initial $\mathrm{pH}$ of the solution (range of 5-9) on the removal efficiency of methylene blue by the rice husk silica (adsorbent dose of $1 \mathrm{gL}^{-1}$ with $50 \mathrm{mgL}^{-1}$ methylene blue and a contact time of 60 minutes) was investigated.

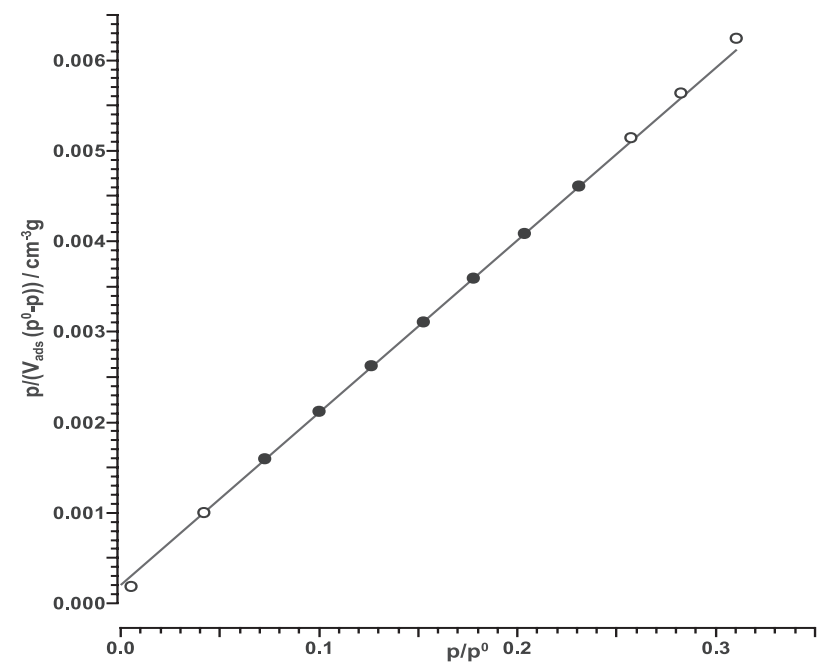

Fig. 2. Surface area (B.E.T.) 2 parameters line (p/po Vs. $p /$ $\left(\operatorname{Vads}\left(\mathrm{p}^{\mathrm{o}}-\mathrm{p}\right)\right) / \mathrm{cm}^{-3} \mathrm{~g}$ in the rice husk silica.

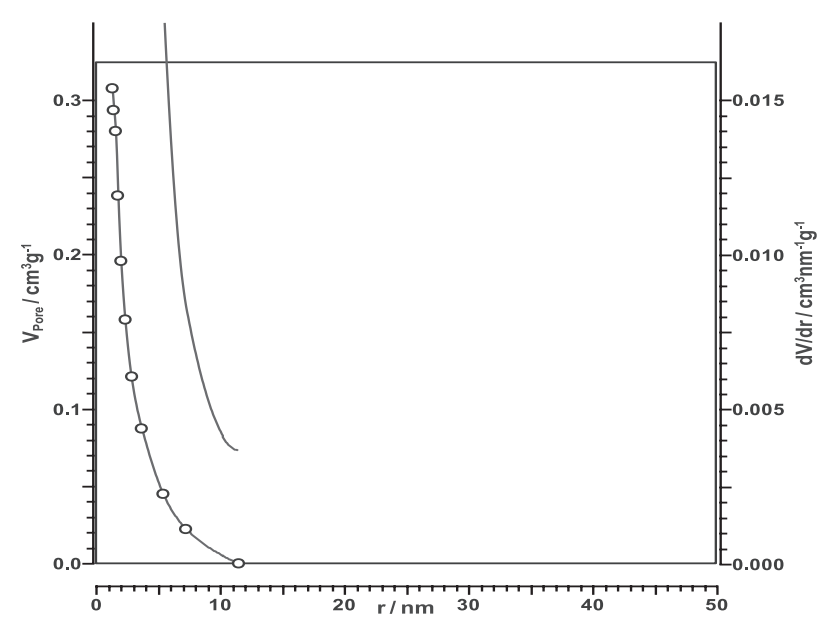

Fig. 3. Pore radius size (nm) vs. pore volume $\left(\mathrm{cm}^{3} \mathrm{~g}^{-1}\right)$ in the rice husk silica prepared at $800^{\circ} \mathrm{C}$. 
a)

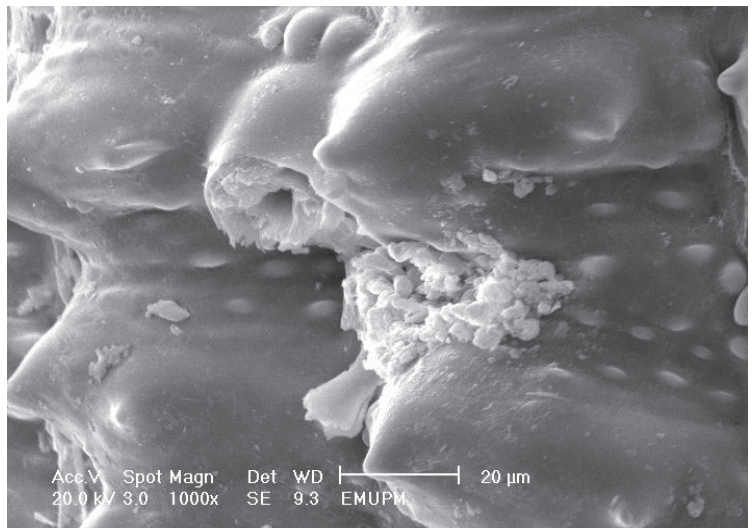

b)

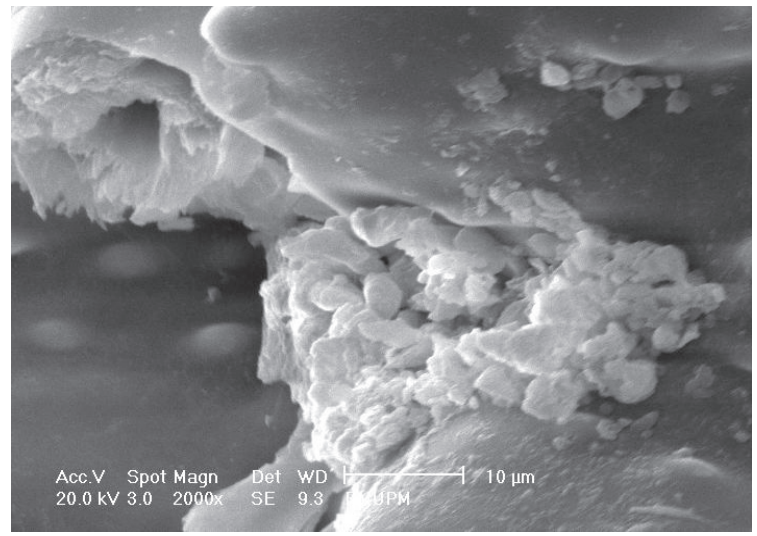

Fig. 4. Scanning electron microscopy (SEM) micrograph of the rice husk silica with magnification of a) 1000 and b) 2000 times.

a)

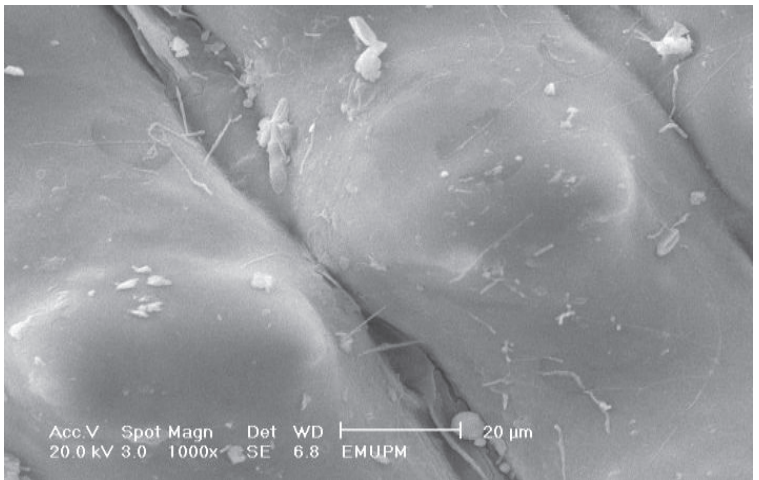

b)

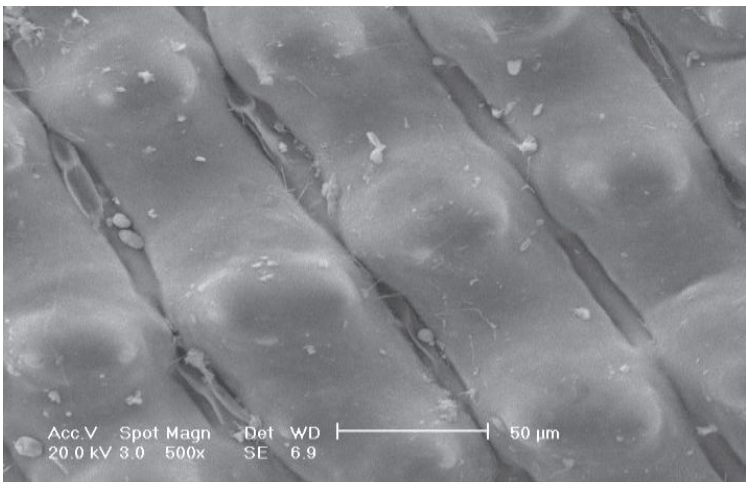

Fig. 5. Scanning electron microscope (SEM) of raw rice husk with magnification a) 500 and b) 1000 times.

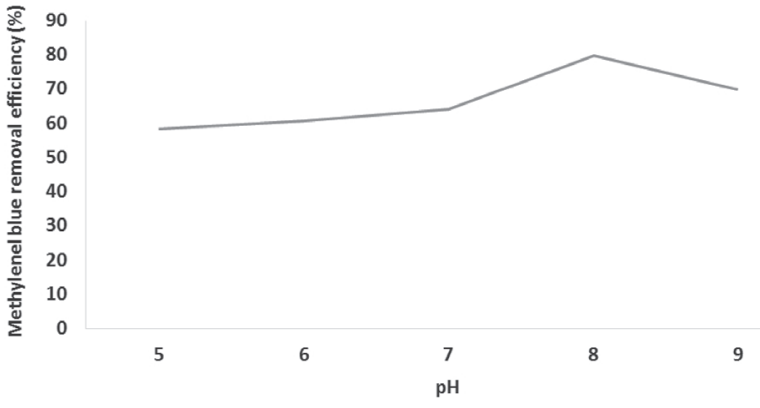

Fig. 6. Effect of the initial solution's $\mathrm{pH}$ on the removal efficiency of methylene blue by rice husk silica.

According to Fig. 6, it has been determined that the best $\mathrm{pH}$ for the adsorbent is 8 . Removal efficiency $(\mathrm{pH} 8)$ was $79.8 \%$.

The results of this study show that the highest removal efficiency of methylene blue by the rice husk silica was for $\mathrm{pH} 8$, contact time of 90 minutes, absorbent mass of $2 \mathrm{gL}^{-1}$, and methylene blue concentration of $10 \mathrm{mgL}^{-1}$ to be $96.7 \%$. In 2013, Jafariansourian et al. conducted a study on the removal of methylene blue by walnut shell ashes. They reported the highest removal efficiency in the removal efficiency for $\mathrm{pH} 10$, a contact time of 150 minutes, an adsorbent dose of $3 \mathrm{gL}^{-1}$, and methylene blue concentration of $100 \mathrm{mgL}^{-1}$ to be 93.25\% [30]. In another study conducted by Bazrafshan et al. in 2012, the removal of methylene blue by the ashes of the Parsica stem was the most efficient for $\mathrm{pH}$ 13 , the adsorbent mass of $156.2 \mathrm{gL}^{-1}$, and the methylene blue concentration of $80 \mathrm{mgL}^{-1}$ was $97 \%$ [9].

\section{Results of the Effect of Initial Methylene Blue Concentrations}

To study the effect of initial concentrations of methylene blue on removal efficiency, the methylene blue variable was investigated at different concentrations by keeping the value of other effective factors constant. In Fig. 7, the methylene blue removal efficiency is provided for the rice husk silica at $\mathrm{pH} 8$, with an

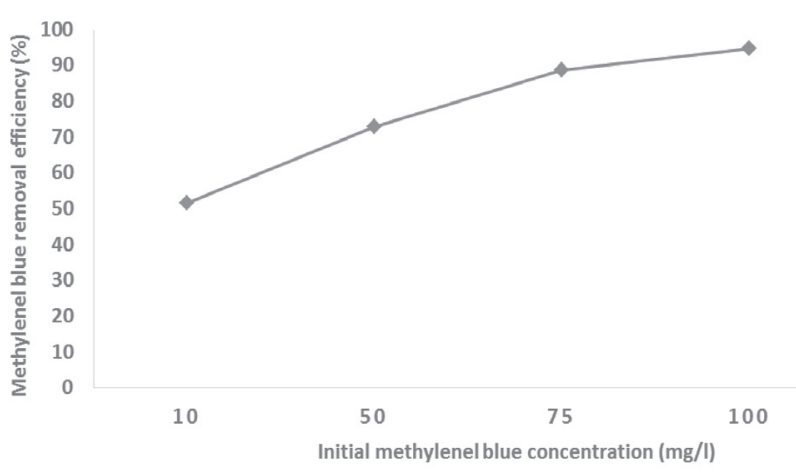

Fig. 7. Effect of the initial methylene blue concentration on the removal efficiency of methylene blue by the rice husk silica. 
adsorbent dose of $1 \mathrm{gL}^{-1}$ and contact time of 60 minutes at different concentrations of methylene blue (10, 50, 75 , and $100 \mathrm{mgL}^{-1}$ ). As shown in Fig. 7, by increasing the initial concentration of methylene blue, the removal efficiency could be decreased. The removal efficiency at an initial concentration of $10 \mathrm{mgL}^{-1}$ is obtained as $96.7 \%$. After increasing the methylene blue concentration to $100 \mathrm{mgL}^{-1}$, the removal efficiency decreased to $60.8 \%$.

Moreover, this study shows that increasing the initial concentration of methylene blue reduces the removal efficiency; therefore, for $\mathrm{pH} 8$, the adsorbent mass of $1 \mathrm{gL}^{-1}$, contact time of 60 minutes, and initial concentration of $100 \mathrm{mgL}^{-1}$ methylene blue, the removal efficiency would be $96.7 \%$. In similar conditions, the removal efficiency will get reduced to $60.8 \%$ if the concentration is increased to $100 \mathrm{mgL}^{-1}$. This result is consistent with the results obtained by Dejene et al. in 2016 [28] and Ghoreyshi et al. in 2014 [29]. Moreover, Jafarimansorian et al. in 2013 reported in their study on the removal of methylene blue by means of walnut shell ashes that the efficiency will be reduced if the initial concentration of methylene blue is increased. They proved that for a contact time of 150 minutes, an adsorbent dose of $3 \mathrm{gL}^{-1}, \mathrm{pH} \mathrm{10}$, and an increase in the concentration from 25 to $100 \mathrm{mgL}^{-1}$ reduced the removal efficiency from $93.25 \%$ to $85.45 \%$ [30]. This may be due to a decrease in the active level of adsorbent surfaces. In high concentrations, active bands are less available to pollutants and therefore the speed of mass transfer in these concentrations is reduced. In other words, at low concentrations the ratio of available surface to the initial concentration of pollutants is larger and thus the removal becomes independent of initial concentrations. However, in the case of higher concentrations, this ratio is low and therefore the removal efficiency depends on the initial concentration [28].

\section{The Effects of the Adsorbent Mass}

For investigating the effect of various doses of the adsorbent mass on removal efficiency, the variable of adsorbent mass in different doses was investigated while keeping the values of other effective factors constant. The results of the methylene blue removal efficiency for different doses of the rice husk silica $(0.5$, $1,1.5$, and $\left.2 \mathrm{gL}^{-1}\right)$ at the methylene blue concentration of $50 \mathrm{mgL}^{-1}, \mathrm{pH} 8$, and contact time of 60 minutes have been shown in Fig. 8. According to this figure, an increase in the amount of the adsorbent increases the removal efficiency significantly - for instance, for an adsorbent dose of $0.5 \mathrm{gL}^{-1}$, the removal efficiency was $51.7 \%$. After increasing the amount of adsorbent to $2 \mathrm{gL}^{-1}$, the removal efficiency increased to $94.8 \%$.

The results of this study show that reducing the adsorbent mass reduces removal efficiency; therefore, for $\mathrm{pH} 8$, a methylene blue concentration of $50 \mathrm{mgL}^{-1}$, contact time of 60 minutes, and adsorbent mass of $2 \mathrm{gL}^{-1}$, the removal efficiency would be $94.8 \%$.

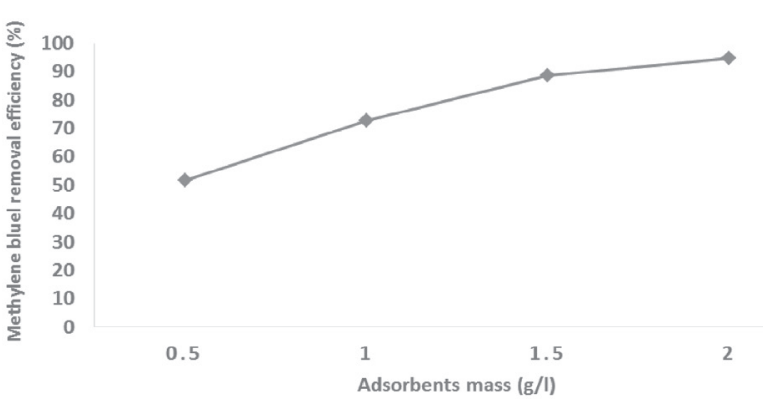

Fig. 8. The effect of adsorbent mass on methylene blue removal efficiency by the rice husk silica.

Under similar conditions, the removal efficiency will be reduced to $51.7 \%$ if the adsorbent mass is reduced to $0.5 \mathrm{gL}^{-1}$. Bazrafshan et al. in 2012 reported in their study that the removal efficiency of methylene blue increases due to an increase in adsorbent mass [9].

\section{Results of the Impact of Contact Times}

For investigating the effect of different contact times of the adsorbent with methylene blue in aqueous solutions we used the Pearson correlation test. The contact time variable was investigated from 30-90 minutes while maintaining constant values of other factors that affect adsorption. The results of the effect of different contact times $(30,45,60,75$, and $90 \mathrm{~min}$ ) at an initial concentration of methylene blue of $50 \mathrm{mgl}^{-1}$, adsorbent dose of $1.0 \mathrm{gl}^{-1}$, and optimal $\mathrm{pH}$ of 8 for the rice husk silica are presented in Fig. 9. Based on the results presented in this graph, any increase in the contact time increases the methylene blue removal efficiency. The removal efficiency for the rice husk silica at 30 minutes of contact time was $72.4 \%$. After increasing the contact time to 90 minutes, the removal efficiency increased to $93.4 \%$. As Fig. 9 shows, a strong and significant correlation between increasing contact times and removal efficiency

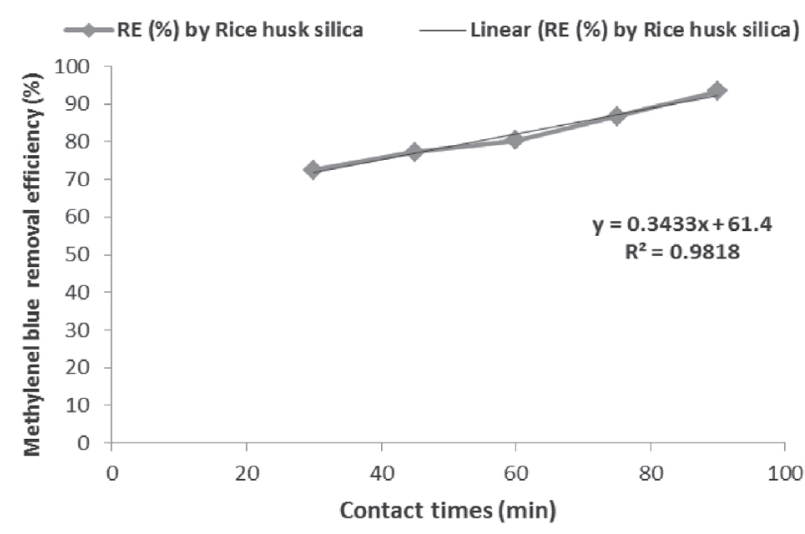

Fig. 9. The correlation between increasing contact times and methylene blue removal efficiency at $\mathrm{pH} 8$, adsorbent dosage of $1.0 \mathrm{gl}^{-1}$, and $50 \mathrm{mgl}^{-1}$ of the initial concentration of methylene blue by the rice husk silica. 
Table 2. Langmuir and Freundlich isotherm constants on the adsorption of methylene blue on rice husk silica.

\begin{tabular}{|c|c|c|c|c|c|c|}
\hline \multicolumn{3}{|c|}{ Isoterm } \\
\hline \multicolumn{3}{|c|}{ Freundlich } & \multicolumn{5}{c|}{ Langmuir } \\
\hline $\mathrm{R}^{2}$ & $\mathrm{n}$ & $K_{f}$ & $\mathrm{R}^{2}$ & $K_{l}$ & $q_{\max }$ & $R_{l}$ \\
\hline 0.9826 & 1.61 & 20.3 & 0.9962 & 4.40 & 103.11 & 0.041 \\
\hline
\end{tabular}

has been detected for the rice husk silica adsorbent $(\mathrm{p}<0.01)$

In addition, the results of this study show that if all other parameters are constant, the increase in contact time would increase removal efficiency. For $\mathrm{pH} 8$, the methylene blue concentration of $50 \mathrm{mgl}^{-1}$ and the adsorbent mass of $1 \mathrm{gl}^{-1}$ for a contact time of 30 minutes increased from $72.4 \%$ to $93.4 \%$ for a contact time of 90 minutes. Ramavandi et al. in 2014 conducted a study on the removal of methylene blue from aquatic solutions by shrimp shells. These researchers have shown that any increase in the contact time would increase removal efficiency [6].

\section{The Results of Adsorption Isotherms}

Langmuir and Freundlich isotherms were used to analyze the adsorption of methylene blue by the rice husk silica. The correlation coefficients of the curve for these adsorption models have shown a better matching of methylene blue adsorption with the Langmuir isotherm model. Table 2 presents the coefficients of these isotherms. According to the correlation coefficient of the models, methylene blue adsorption is derived from the Langmuir model.

\section{Conclusions}

The rice husk silica showed more porosity than the raw rice husk with a median pore radius of $2.4 \mathrm{~nm}$ and high specific surface area of up to $226.3 \mathrm{~m}^{2} \mathrm{~g}^{-1}$. More porosity of adsorbents causes more removal efficiency because of the number of adsorption sites. It was possible to remove of methylene blue from aqueous solutions by using the silica derived from the raw rice husk. The $\mathrm{pH}$ of the solution plays an important role in the adsorption process. The $\mathrm{pH}$ selected to give an optimum rate of adsorption is 8 . The maximum removal efficiency of methylene blue by the rice husk silica under the initial concentration of $10 \mathrm{mgL}^{-1}$ methylene blue, $1 \mathrm{gL}^{-1}$ adsorbent mass, $60 \mathrm{~min}$ contact time, and $\mathrm{pH} 8$ was $96.7 \%$. The correlation coefficients of the adsorption models have shown a better matching of methylene blue adsorption by the rice husk silica with the Langmuir isotherm model. The rice husk silica has an advantage, as it can be applied to remove environmental pollutants, such as methylene blue, in developing countries due to the low cost and availability of the rice husk.

\section{Acknowledgements}

This research was financially supported by Semnan University of Medical Sciences through project No. 1149. The authors thank the university for research funding.

\section{Conflict of Interest}

The authors declare that they have no conflicts of interest.

\section{References}

1. ZIYAPOUR A.R., HAMZEH Y., ABYAZ A. The use of soybean as an adsorbent for acid orange color removal from aqueous solution. Journal of separation science and Engineering, 4 (2), 29, 2013.

2. ANSARI R., MOHAMMADKHAN A., ALAIE S. Removal of anionic dye conggo red from aqueous solutions using sawdust modified by polyaniline: Adsorption isotherm and kinetics study. Journal of Color Science and Technology, 5 (4), 335, 2012.

3. SHOKOUHI M., FAGHIHIAN H., NOURMORADI $\mathrm{H}$. Investigating the modified silica aerogel removal efficiency on removing the heavy metals from aqueous solutions. Journal of Health system research, 4, 974, 2011.

4. KAFI Z., GANJIDOUST H., AYATI B. Study of dye removal from aqueous solution using sawdust and clay. Modares Civil Engineering Journal, 11 (3), 67, 2011.

5. RAHMANI A.R., ASGARI G., FARROKHI M., SHIRZAD M. Removal of reactive black 5 (RB5) dye from aqueous solution using adsorption onto strongly basic anion exchange resin: Equilibrium and kinetic study. Iranian J Health Environ., 5 (4), 509, 2013.

6. RAMAVANDI B., LEILI M. Efficiency of shrimp shell to remove Methylene Blue from aqueous solutions. J. Health, 5 (4), 310, 2015.

7. JAFARNEJAD E., NEMATI J. Methylene blue dye removal from aqueous solutions and photocatalytic activity using UV/Nano-TiO: operating parameters study, Anal. Chem. Lett., 5 (4), 192, 2015.

8. GHANIZADEH G., Asgari G, Removal of methylene blue dye from synthetic wastewater with bone char. Iranian J. Health and Environ., 2 (2), 104, 2009.

9. BAZRAFSHAN E., KORD-MOSTAFAPOUR F. Evaluation of color removal of methylene blue from aqueous solutions using plant stem ash of persica. J. North Khorasan Univ. Med. Sci., 4 (4), 523, 2013.

10. MAJLESI M., YAZDANBAKHSH A.R., SHEIKHMOHAMMADI A. Evaluation of iron element efficiency 
in on azo dye of industrial effluent. J. Environ. Sci. Technol., 14 (3), 57, 2012.

11. GHANEIAN M.T., EHRAMPOUSH M.H., GHANIZADEH G., MOMTAZ M. Study of eggshell performance as a natural sorbent for the removal of reactive red 198 dye from aqueous solution. Toloo- ebehdasht, 1 (31), 70, 2011.

12. PYRSAHEB M., SHARIFI K., DARGAHI A. Treatment of textile wastewater using inorganic coagulants. Zahedan J. Res. Med. Sci. 14 (29), 2015.

13. ALIJANI S., VAEZ M., ZARRINGHALAM A. S. Comparative study on the photodegradation of acid black 26 from synthetic wastewater using slurry and immobilized $\mathrm{TiO}_{2}$ on the sackcloth fiber. Journal of Health and Environment. 6 (2), 243, 2013.

14. MEHDINIA S.M., ABDULLATIF P., TAGHIPOUR H. A comparative evaluation of dried activated sludge and mixed dried activated sludge with rice husk silica to remove hydrogen sulfide. Iranian J Environ Health Sci Eng., 10 (22), 1, 2013.

15. MEHDINIA S.M., ABDULlATIF P., TAGHIPOUR H. Investigation of the capability of regenerated rice husk silica to remove hydrogen sulfide pollution, Koomesh, 14 (1), 86, 2012.

16. NASSEHINIA H., MAHMOUDI A., MEHDINIA S. M. Cadmium removability from aqueous solutions using $\mathrm{TiO}_{2}$ nano photocatalytic compound and rice husk silica. Koomesh, 18 (3), 334, 2016.

17. MEHDINIA S.M., ABDULlatiF P., TAGHIPOUR H. Removal of hydrogen sulfide by physico-biological filter using mixed rice husk silica and dried activated sludge. Clean Soil Air Water, 41, 949, 2013.

18. MEHDINIA S.M., MOEINAN K., RASTGOO T. Studying the cadmium removal from aqueous solution using raw husk, bran and rice husk silica. J Babol Univ Med Sci., 16 (10), 52, 2014.

19. NASSEHINIA H., RAHMANI A., GHAIENY G., MEHDINIA S.M. Application of novel methods in environmental and health hazardous pollutants removal using nanophotocatalysts. Koomesh, 18 (3), 309, 2016.

20. EATON A., FRANSON M. H. Standard methods for the examination of water and wastewater. 21 ed. American Public Health Association, Washington DC, 2005.

21. NOORI-MOTLAGH Z., DARVISHI R., SHAMSKHORAMABADI G., Ghodini H., FOROUGHI M. Study of the effective parameters on decolorization of methylene blue using UV radiation in the presence of immobilized catalyst. Journal of Ilam University of Medical Sciences, 2 (1), 36, 2013.

22. SARKER N., FAKHRUDDIN A.N.M. Removal of phenol from aqueous solution using rice straw as adsorbent, Applied Water Science, 7 (3), 1459, 2017.

23. ROS A., MONTES-MORAN M.A., FUENTE E., NEVSKAIA D.M., MARTIN M.J. Dried sludge and sludge-based chars for $\mathrm{H}_{2} \mathrm{~S}$ removal at low temperature: Influence of sewage sludge characteristic, Environ. Sci. Technol., 40 (1), 302, 2006.

24. MEHDINIA S.M, ABDULLATIF P, MAKMOMABDULLAH A., TAGHIPOUR H. Synthesize and characterization of rice husk silica to remove the hydrogen sulfide through the physical filtration system. Asian J Sci Res. 4 (3), 246, 2011.

25. CHOUDHURY T.R., PATHAN K.M., NURUL A.M., ALI M., QURAISHI S.B., MUSTAFA A.I. Adsorption of $\mathrm{Cr}$ (III) from aqueous solution by groundnut shell. Journal of Environmental Science and Water Resources, 1 (6), 144, 2012.

26. KHAZAEI I., ALIABADI M., HAMED-MOSAVIAN H.T. Use of agricultural waste for removal of $\mathrm{Cr}(\mathrm{VI})$ from aqueous solution. Iranian J of Chem. Eng., 8 (4), 11, 2011.

27. KAFIA M., SHAREEF S. Agricultural wastes as low cost adsorbent for $\mathrm{Pb}$ removal: Kinnetice, Equilibrium and Thermodynamics. International Journal of Chemistry, $\mathbf{3}$ (3), 103, 2012.

28. DEJENE K., SIRAJ K., KITTE S.A. Kinetic and thermodynamic study of phenol removal from water using activated carbon synthesizes from avocado kernel seed. Int. lett. nat. sci., 54, 42, 2016.

29. GHOREYSHI A., PIRZADEHA K. Phenol removal from aqueous phase by adsorption on activated carbon prepared from paper mill sludge. Desalination and Water Treatment, 5, 6505, 2014.

30. JAFARI-MANSOORIAN H., MAHVI A. H., KORDMOSTAFAPOOR F., ALIZADEH M. Equilibrium and synthetic studies of methylene blue dye removal using ash of walnut shell. Journal of Health in the Field, 1 (3), 48, 2013. 
